\title{
Thermally induced structural changes in Nomex fibres
}

\author{
ANJANA JAIN and KALYANI VIJAYAN* \\ Materials Science Division, National Aerospace Laboratories, Bangalore 560 017, India
}

MS received 21 March 2002

\begin{abstract}
Thermally aged Nomex fibres manifest several residual effects viz. reduction in X-ray crystallinity, weight loss and deterioration in tensile characteristics. Surface damages in the form of longitudinal openings, holes, material deposits etc have also been observed. Based on the data from thermally exposed fibres, the time needed for states of zero tensile strength and modulus have been predicted.
\end{abstract}

Keywords. Nomex; thermal ageing; X-ray diffraction; structural changes.

\section{Introduction}

Nomex fibres made up of poly $(m$-phenylene isophthalamide) or PMIA (Tadokoro 1979), the structural formula of which is shown below, belong to the class of aramids. Although sheets of Nomex are commonly used as dielectric (DuPont 1981), fibres also find application as structural components in aircraft and helicopters (Marks 1995). They are also recommended for use at elevated temperatures (Carlson et al 1973). Tanner et al (1988) mention about fire protective apparel made of a blend of Nomex and Kevlar, the latter being the para substituted isomer of Nomex (Meredith 1975). In this context, it is of interest to gain knowledge about the response of these fibres to thermal environments. Detailed analyses have been carried out in the past to identify the effect of thermal exposures on the initial characteristics of Kevlar fibres (Hindeleh and Abdo 1989; Shubha 1989; Parimala 1991; Parimala and Vijayan 1993; Iyer and Vijayan 1994, 1998a,b, 1999; Iyer 1999; Jain and Vijayan 2000). This paper presents the results of observations on the residual effects of thermal exposures on the meta substituted Nomex fibres derived by X-ray diffraction methods, scanning electron microscopy, tensile testing and analysis of weight.

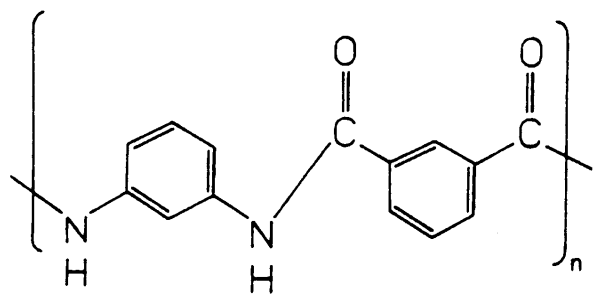

*Author for correspondence

\section{Experimental}

Samples used were the Nomex fibres made commercially available by DuPont Inc., USA. Unconstrained bundles of fibres $\sim 2 \mathrm{~mm}$ thick and $\sim 50 \mathrm{~mm}$ in length were subjected to thermal exposures in air. The temperatures $(T)$ chosen were $200,300,350$ and $400^{\circ} \mathrm{C}$. Of these, only $200^{\circ} \mathrm{C}$ is within the recommended limit of service temperature, viz. $220^{\circ} \mathrm{C}$ (DuPont 1981) and also less than the $T_{\mathrm{g}}$ value $\left(>230^{\circ} \mathrm{C}\right)$ (Tashiro et al 1977). Choice of temperatures close to and well above these limits was deliberate and was intended to enable accelerated data collection and provide results which may subsequently be extrapolated. Durations of cumulative exposure, $t_{\text {cum }}(T)$ to various $T$ 's, ranged from 0.5 to few 1000's of hours. The choice of the $t_{\text {cum }}(T)$ values was arbitrary. A tubular resistance furnace in which the temperature could be controlled and maintained to an accuracy of $\pm 2^{\circ} \mathrm{C}$ was used to conduct the thermal exposures. Fibres were placed in a quartz tube $\sim 1.2 \mathrm{~cm}$ in i.d. The quartz tube was slid into the furnace in such a manner that the fibres occupied the central, constant temperature zone of the furnace. The temperature of the sample was measured using a chromel-alumel thermocouple placed very close to the sample. Prior to and at various stages of thermal ageing, the fibres were characterized. The parameters used for characterization were X-ray crystallinity, tensile strength, tensile modulus, microstructural features and weight. At $200^{\circ} \mathrm{C}$, only the crystallinity changes have been identified. It must be mentioned that for each of the chosen temperatures, separate bundles of fibres were used to identify the relative changes in crystallinity, weight loss, surface characteristics and tensile properties. Handling losses were also minimized by encasing the bundles in small tubes. Details of the experimental procedures followed are described below. 
Wide angle X-ray diffraction patterns were recorded to identify changes in crystallinity. A Philips powder diffractometer with a graphite monochromator in the diffracted beam and a proportional counter was used to record the equatorial patterns in the reflection geometry. $\mathrm{CuK} \alpha$ radiation was employed. The diffraction patterns were confined to the $2 \theta$ range of 10 to $45^{\circ}$, beyond which no observable reflections could be detected. It is well known that the diffraction intensities are related to the crystallinity of the sample. As the present study was concerned only with the identification of relative changes in crystallinity introduced by thermal ageing, no attempt was made to estimate the absolute values of crystallinity. Quantitative estimates of thermally induced changes in crystallinity were, however, obtained by comparing the appropriate integrated intensities of the diffraction profiles. For example, the ratio $k=I_{\mathrm{t}}^{T} / I_{0}$ represents the fractional value of the crystallinity of fibres exposed to temperature $T$ for the cumulative time duration $t_{\text {cum }}(T)$. Here, $I_{0}$ and $I_{\mathrm{t}}^{T}$ represent the integrated intensities, prior to and after thermal exposure, respectively. In each pattern, the contribution to the I's from the respective amorphous fraction (to be described subsequently) has also been removed. Integrated intensities were estimated by measuring the area under the diffraction profiles, using a digitiser and an Autocad system. In order to estimate the standard deviation (esd) of the integrated intensities thus measured, patterns were recorded from a bundle of fibres, referred to as 'standard', at periodic intervals of time and their integrated intensities were measured. The standard deviation estimated from a set of 50 patterns recorded from the same 'standard' was $\sim 2 \%$.

Tensile strength and modulus of individual filaments were estimated using a Zwick universal testing machine. A gauge length of $25 \mathrm{~mm}$ and strain rate of $10 \mathrm{~mm}$ per min were used. For each of the experimental conditions, at least 50 filaments were examined and the average values of tensile properties were estimated. A Jeol scanning electron microscope was used to examine the surface features of gold coated fibres. It must be emphasized that care was taken to avoid manually introduced artefacts and deformations. Prior to examination in the microscope, the surface of fibres were not manually touched or subjected to any type of bending, twisting etc. Percentage variation in weight accompanying thermal ageing was estimated as $\left(\Delta w / w_{0}\right) \times 100$, using a Sartorius analytical balance capable of reading down to $0.0001 \mathrm{~g}$. Here, $\Delta w=w_{0}-w_{\text {heat treated, }} w_{0}$ and $w_{\text {heat treated }}$ are the weights of samples prior to and after heat treatment, respectively. The latter weight was measured within five minutes of removing the sample from the furnace and cooling to ambient temperature. For each of the chosen experimental conditions, at least three sets of samples were examined and the average value of weight loss was estimated.

\section{Results and discussion}

\section{$3.1 X$-ray crystallinity}

Figure 1 presents a typical example of the influence of heat treatment on the diffraction profiles. Here, the equatorial patterns recorded prior to and at various stages of cumulative exposure to $200^{\circ} \mathrm{C}$ are shown. The observed reflections in the pattern include $(100)+(010),(101)$ $+(011)+(\overline{1} \overline{1} 1),(110)$ and $(200)+(020)$ occurring at $\sim 2 \theta$ values of $18.2,23.4,27.4$ and $36 \cdot 8^{\circ}$, respectively. The + sign in the above notation indicates overlapping reflections. The indices of reflections are based on the triclinic unit cell proposed by Kakida et al (1976). Conspicuously, even prior to thermal exposures, the intensities of the reflections are not very high and in addition they are also superposed on a broad, diffuse background at low angles. These features are indeed indications of the 'not so very crystalline' nature of the sample. Kakida et al mention that in samples with low crystallinity, an additional equatorial reflection corresponding to $d=$ $6.9 \AA\left(2 \theta \approx 12.9^{\circ}\right.$ for $\mathrm{CuK} \alpha$ radiation $)$ should occur. The patterns in figure 1 show the occurrence of this reflection and thus provide further evidence for the presence of an amorphous fraction in the samples used.

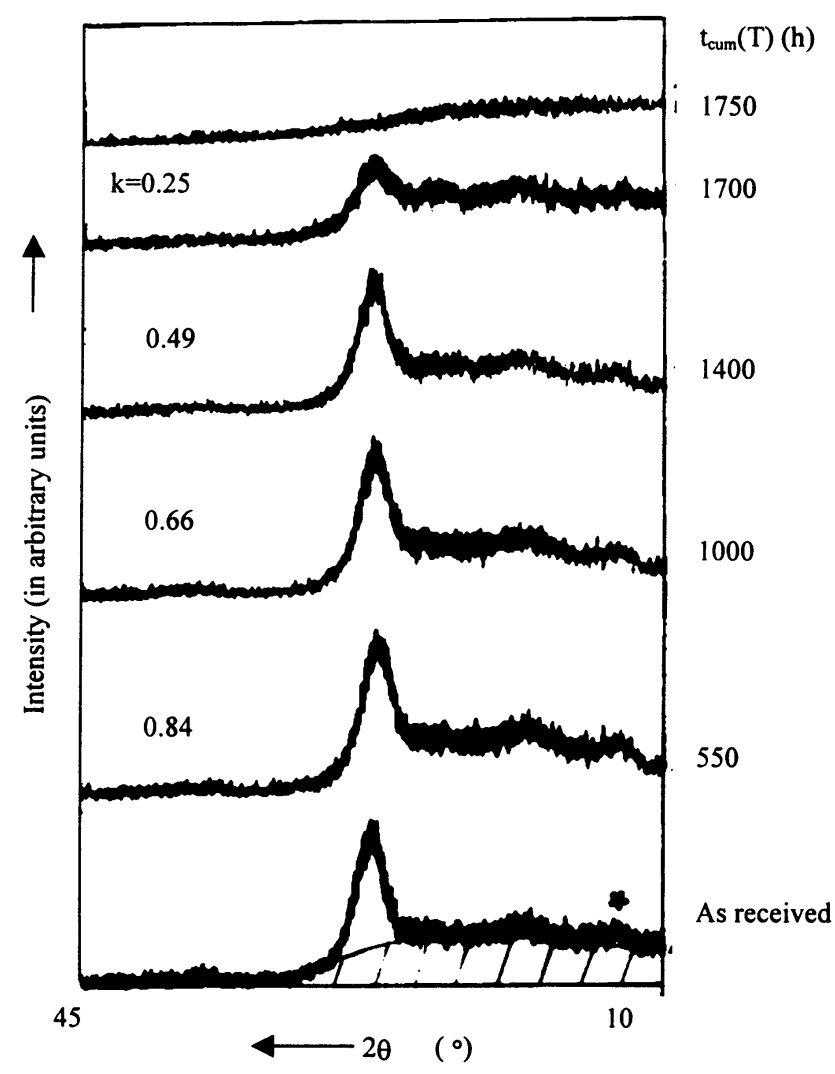

Figure 1. Comparison of X-ray diffraction profiles recorded prior to and at various stages of exposure to $200^{\circ} \mathrm{C}$. Values of $t_{\text {cum }}(200)$ and $k=I_{t}^{T} / I_{0}$ have also been marked. The additional reflection at $2 \theta=12.9^{\circ}$ has been indicated by an asterisk mark. 
Figure 1 shows the progressive diminution in the diffraction intensity and the corresponding variation in the value of $k$. The contribution from the amorphous fraction has been removed in the estimation of $k$ values (Wakelin et al 1959). It may be noticed that after $1750 \mathrm{~h}$ of exposure, no Bragg reflections are observable in the diffraction pattern. This feature shows that as a result of the continuous exposure to $200^{\circ} \mathrm{C}$, the sample reached a state of zero crystallinity. Similar states of zero crystallinity were reached after prolonged exposures to other $T$ 's also. Figure 2 presents the non linear variation of $k$ as a function of $t_{\text {cum }}(T)$ for various $T$ values. As could be expected, for a chosen value of $t_{\text {cum }}(T)$, the reduction in crystallinity increases with $T$. Also, for a chosen value of $T$, the crystallinity decreases with prolonged ageing at that temperature. The two parameters which characterize any thermal exposure viz. $T$ and $t_{\text {cum }}(T)$, thus appear to influence the thermally induced reduction in X-ray crystallinity.

When the fibres reached the state of zero crystallinity due to ageing at various temperatures, the diffuse background in the diffraction pattern was found to persist. At these stages, the respective samples had turned black and brittle. These features suggest that an amorphous fraction, perhaps carbonized, persisted in the sample.

\subsection{Weight loss}

Thermal ageing of Nomex fibres is accompanied by weight loss the details of which are presented in figure 3 . The esd's of individual weight losses range from 0.12 to 1 and thus most of the observed changes are statistically significant. As in the case of crystallinity, the weight loss

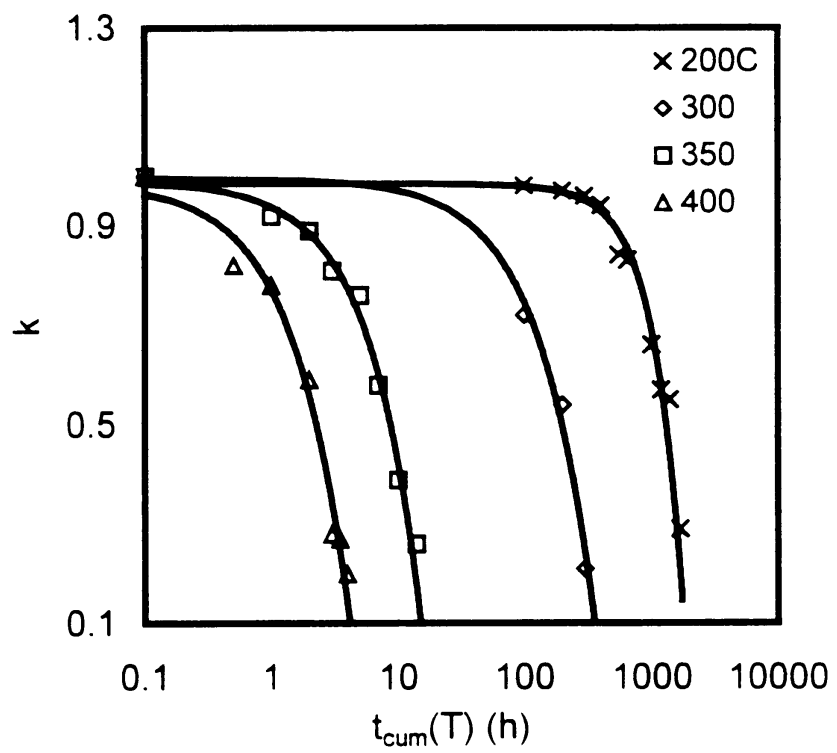

Figure 2. Fractional variation in crystallinity at various temperatures. is also controlled by the values of both $T$ and $t_{\text {cum }}(T)$. Weight loss may be attributed to chemical reactions and/or degradation introduced during heat treatment, leading to the formation and subsequent emanation of small molecular weight compounds, gaseous components etc from the sample. Experimental evidence for such an evolution of components from within the fibres has been obtained from the scanning electron micrographs, the details of which follows.

\subsection{Surface characteristics}

Figures $4 \mathrm{a}$ and $\mathrm{b}$ present the micrographs depicting the surface characteristics of Nomex fibres prior to heat treatment. The conspicuous feature concerns the presence of dark lines running longitudinally (figure 4a). In addition, small specks of some extraneous material (figure $4 b$ ) are also found to be distributed on the surface, in a random fashion.

Figures $4 \mathrm{c}-\mathrm{f}$ illustrate the various surface characteristics of heat treated fibres. Figures $4 \mathrm{c}$ and $\mathrm{d}$ are from fibres exposed to $400^{\circ} \mathrm{C}$ for 2.25 and $4.5 \mathrm{~h}$, respectively. The former shows a groove like opening and the latter depicts the introduction of large quantities of material deposits. In figure $4 \mathrm{c}$ also lesser amounts of such deposits are seen. The proximity of the deposit to an opening suggests that the extraneous material has perhaps come out of the opening. The chemical nature of the deposits have not, however, been identified. In addition to the grooves, minute holes are also found on the surface. The arrow in figure $4 \mathrm{c}$ shows a typical hole.

The above mentioned surface features observed at $400^{\circ} \mathrm{C}$ are seen at lower $T$ 's too. Figure $4 \mathrm{e}$ illustrates the

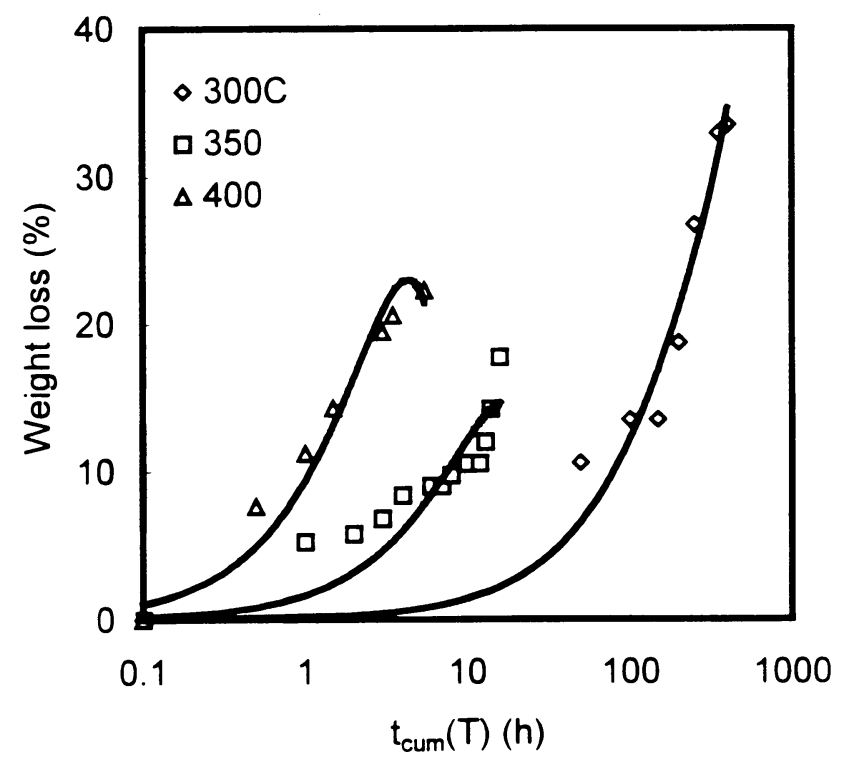

Figure 3. Weight loss (\%) at various temperatures. 
longitudinal groove like openings and holes observed in fibres exposed to $300^{\circ} \mathrm{C}$ for $400 \mathrm{~h}$. Comparison of the micrographs in figures $4 \mathrm{c}$ and e shows that the grooves are more in number and are also deeper in the latter set. The holes which are distributed conspicuously in the vicinity of the longitudinal openings are also more numerous and bigger in size than in fibres heat treated at $400^{\circ} \mathrm{C}$ (figure $4 \mathrm{c}$ ). The intensity of the thermally induced effects are thus more pronounced in fibres exposed to $300^{\circ} \mathrm{C}$ than in the fibres exposed to the higher temperature of $400^{\circ} \mathrm{C}$. Such an enhancement of surface effects observed at the lower of the two temperatures may appear anomalous. However, it is primarily due to the role of the parameter, $t_{\text {cum }}(T)$. At $300^{\circ} \mathrm{C}, 400 \mathrm{~h}$ of exposure introduces more damage to the surface than the $2 \cdot 25$ h of exposure to $400^{\circ} \mathrm{C}$.

It must be pointed out that introduction of the groove like opening, holes and deposits are features which conform well with the weight loss described in the previous section. The holes, in particular, may be associated with the evolution of gaseous components from within the fibre. Interestingly, in all the thermally aged Nomex fibres, the groove like openings are more conspicuously formed than the holes. It is also noticed that the thermally induced grooves fall on the dark lines observed prior to heat treatment (figure 4a). It is not unlikely that the dark lines represent structurally weak regions which are vulnerable to treatments which in this case is thermal in nature.

Yet another thermally induced effect is the introduction of peel offs. Figure 4f shows a typical example in which a peel off is curling around the fibre exposed to $350^{\circ} \mathrm{C}$ for $16 \mathrm{~h}$.

\subsection{Tensile characteristics}

The thermally induced effects described in the previous sections suggest changes in the tensile properties of fibres. Figure 5a presents typical load-extension curves recorded prior to and after heat treatment, respectively. In all the curves, the initial, linear portion suggesting an elastic behaviour is followed by an yield and a subsequent non linear portion. For the various sets of samples, the tensile modulus $(M)$ from the initial linear portion, the tensile strength $(S)$ at fracture and the percentage elongation at break $(\varepsilon)$ were determined.
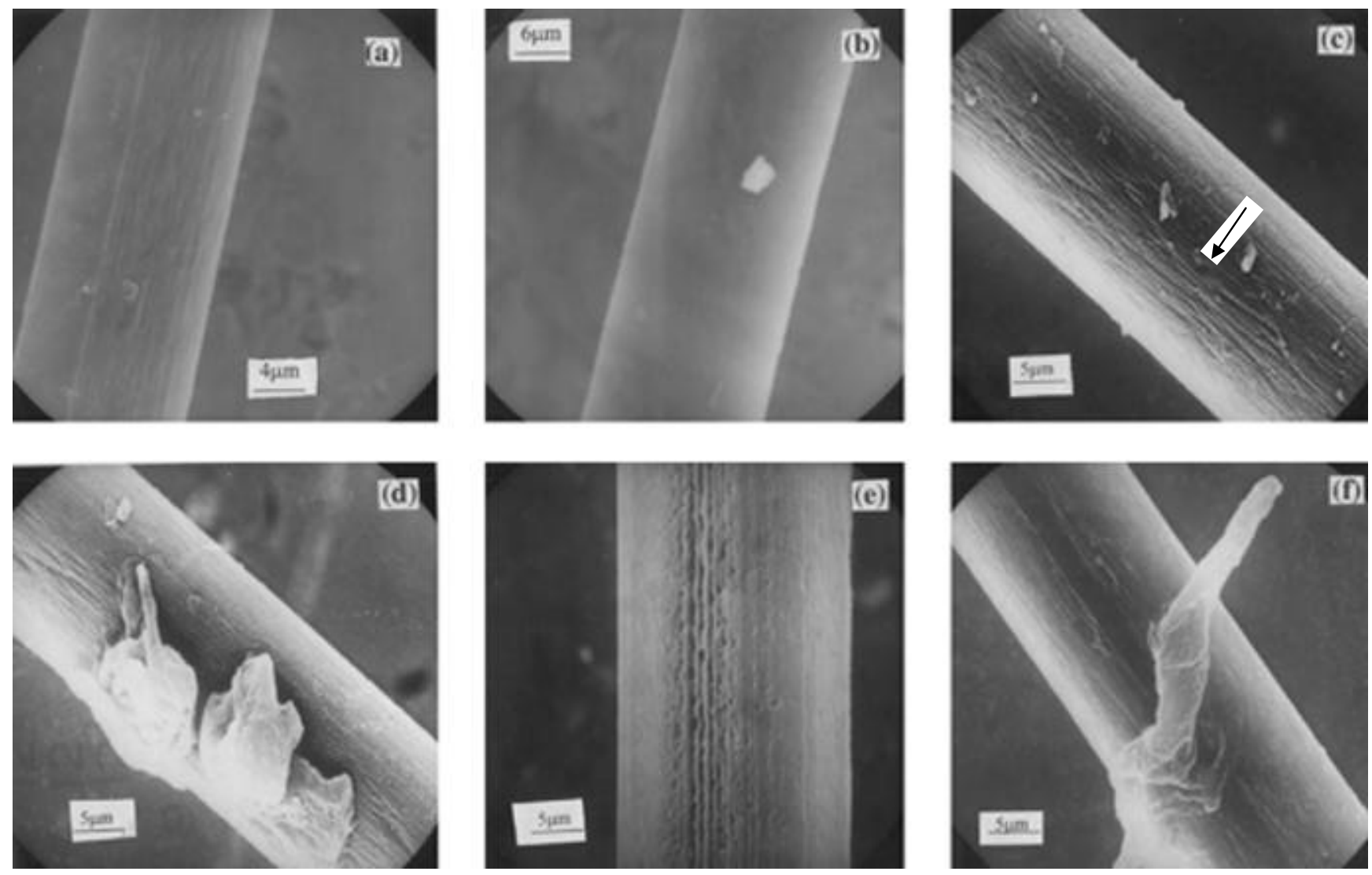

Figure 4. Scanning electron micrographs of (a) longitudinal lines seen prior to heat treatment, (b) a speck of extraneous material, (c) groove like openings seen in fibres exposed to $400^{\circ} \mathrm{C}$ for $2.25 \mathrm{~h}$. Arrow shows a typical hole, (d) material deposits on the surface of a filament exposed to $400^{\circ} \mathrm{C}$ for $4.5 \mathrm{~h}$, (e) surface features of a filament exposed to $300^{\circ} \mathrm{C}$ for $400 \mathrm{~h}$ and (f) a peel off curling around a fibre exposed to $350^{\circ} \mathrm{C}$ for $16 \mathrm{~h}$. 
As seen from figure 5a the striking effects of increase in $T$ on the load-extension curves are (i) the reduction in the breaking stress and strain and (ii) the progressive reduction in the initial slopes. Figure $5 b$ depicts the effect of $t_{\text {cum }}(T)$ on the load-extension curves recorded from fibres exposed to $T=300^{\circ} \mathrm{C}$. Interestingly, the effect of $t_{\text {cum }}(T)$ is very similar to that of $T$. Such a similarity indicates that the deterioration introduced in the initial tensile properties of Nomex fibres is dependant on both the $T$ as well as the $t_{\text {cum }}(T)$ values. Use of the fibres at a chosen temperature for prolonged time intervals, can be as detrimental to the initial properties as by exposing it to various $T$ 's for comparatively short time intervals.

Figures $6 \mathrm{a}, \mathrm{b}$ and $\mathrm{c}$ present the variations in the fractional values of the tensile characteristics. $M_{t}^{T}, S_{t}^{T}$, and $\varepsilon_{t}^{T}$ represent the respective values of modulus, strength and percentage elongation at break after exposure to $T$ for duration $t_{\text {cum }}(T) . M_{0}, S_{0}$ and $\varepsilon_{0}$ are the corresponding
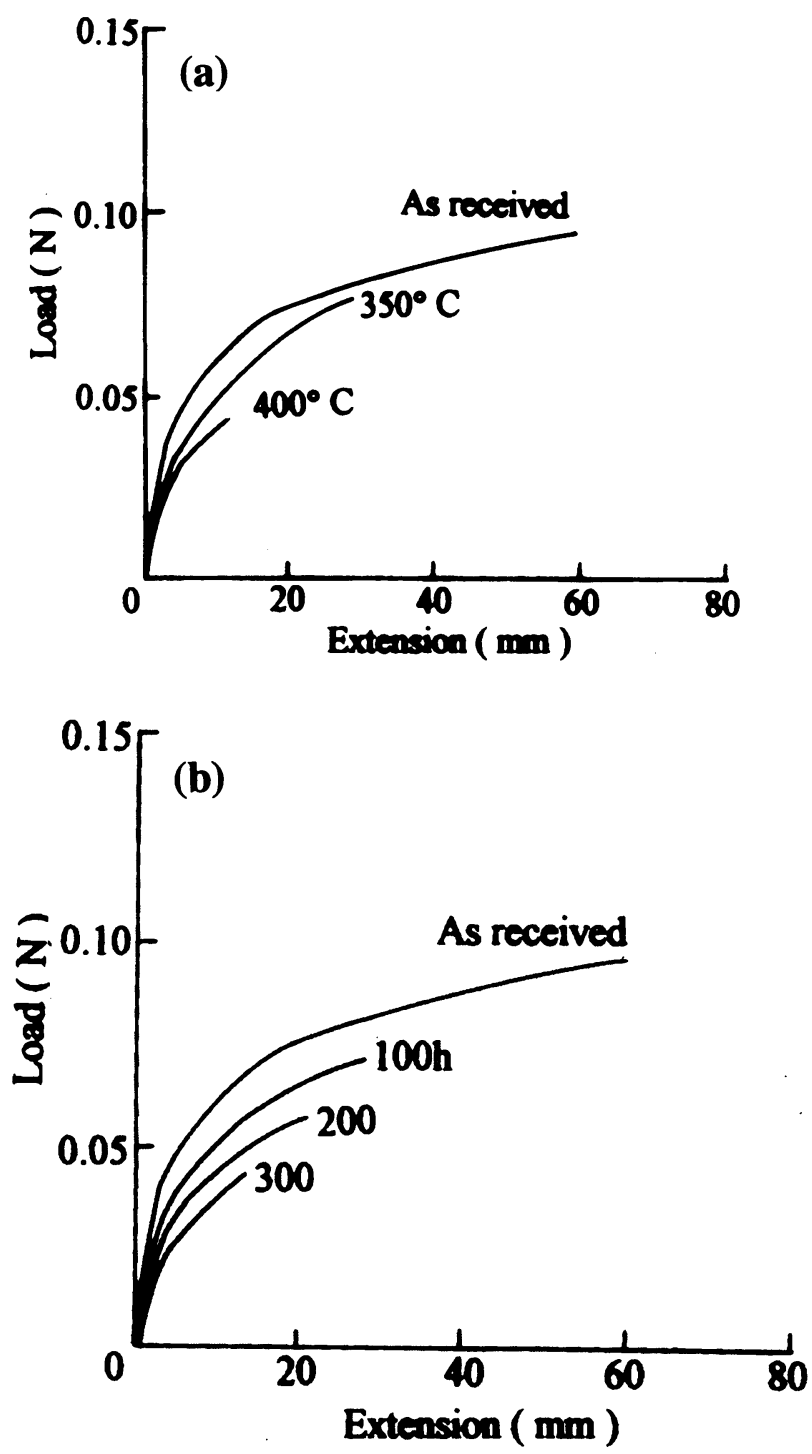

Figure 5. Comparison of load-extension curves: (a) effect of temperature; $t_{\text {cum }}(T)=1 \mathrm{~h}$ and $(\mathbf{b})$ effect of $t_{\text {cum }}(T)$ at $300^{\circ} \mathrm{C}$. values, prior to thermal exposures. For the samples used in this study, values of $M_{0}, S_{0}$ and $\varepsilon_{0}$ were $10(7) \mathrm{GPa}$, $0 \cdot 52(3) \mathrm{GPa}$ and $37 \cdot 4(4) \%$, respectively which compare well with the reported values of $10 \mathrm{GPa}, 0.68 \mathrm{GPa}$ and $35 \%$ (Kasen Geppo 1974). The esd's of the values
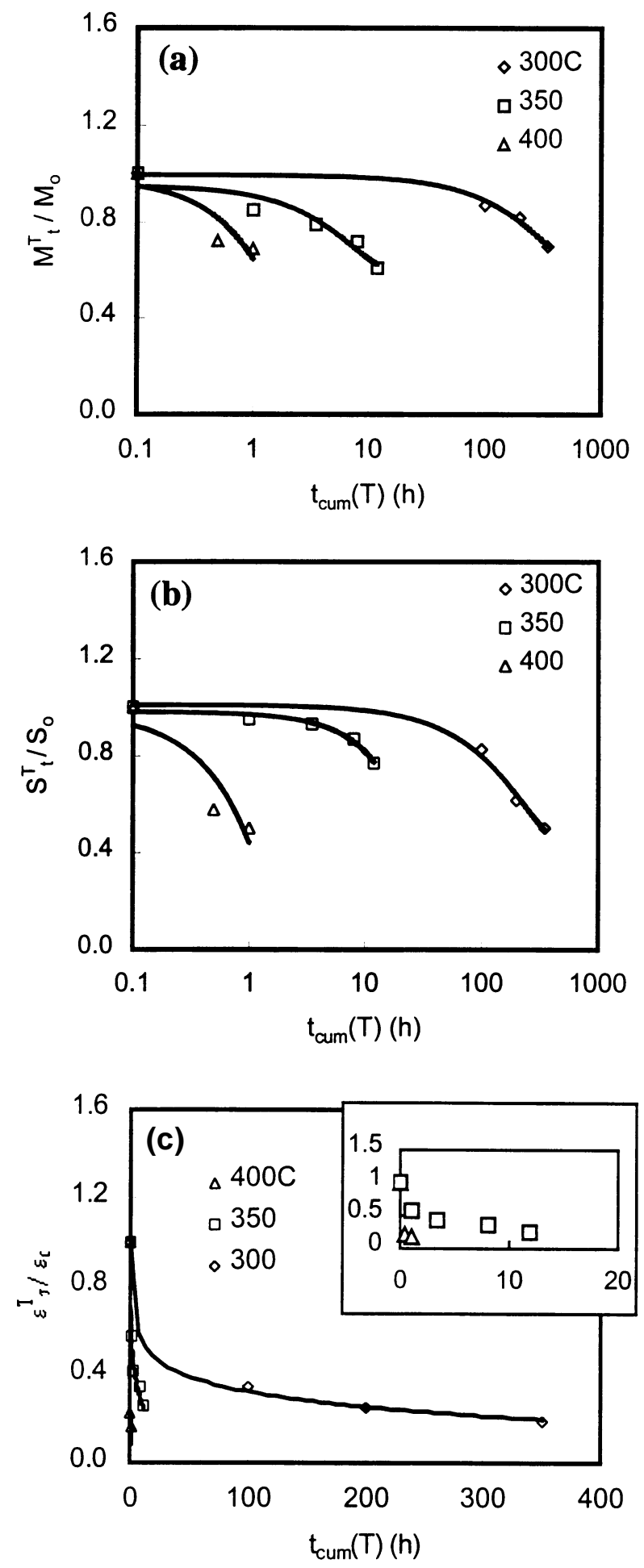

Figure 6. Fractional variations in the tensile characteristics: (a) $M_{t}^{T} / M_{0}$ vs $t_{\text {cum }}(T)$, (b) $S_{\mathrm{t}}^{T} / S_{0}$ vs $t_{\text {cum }}(T)$ and (c) $\varepsilon_{t}^{T} / \varepsilon_{0}$ vs $t_{\text {cum }}(T)$. Inset represents the curves for 350 and $400^{\circ} \mathrm{C}$. 
Table 1. Exposure time (h) needed for 100 and $30 \%$ reductions in tensile modulus and strength.

\begin{tabular}{lcccc}
\hline & \multicolumn{2}{c}{ For tensile modulus } & \multicolumn{2}{c}{ For tensile strength } \\
\hline$T\left({ }^{\circ} \mathrm{C}\right)$ & $t_{100}$ & $t_{30}$ & $t_{100}$ & $t_{30}$ \\
300 & 990 & 300 & 648 & 160 \\
350 & 34 & 9 & 57 & 15 \\
400 & $3 \cdot 1$ & $0 \cdot 8$ & $1 \cdot 9$ & $0 \cdot 4$ \\
\hline
\end{tabular}

recorded in figure 6 , for the heat treated samples are as follows: for the modulus it ranges from 0.4 to $0.9 \mathrm{GPa}$; for the strength from 0.03 to $0.06 \mathrm{GPa}$ and for the percentage elongation at break, from $0 \cdot 13$ to $0 \cdot 15 \%$. As such, most of the observed variations are statistically significant.

The data in figure 6 show that the modulus, strength and percentage elongation at break decrease with increase in the $T$ as well as the $t_{\text {cum }}(T)$ values. For all the three parameters, the variation is comparatively slow at $300^{\circ} \mathrm{C}$. The percentage elongation manifests an interesting behaviour. It is found that in the early stages of isothermal ageing at $300^{\circ} \mathrm{C}$, the changes in $\varepsilon$ occur in large measures and with further progressive ageing, the extent of variation decreases. For Nomex fibres, the initial value of $\varepsilon$, which is $\sim 37 \%$ may be associated with the lesser rigidity and increased flexibility of the PMIA polymer chains, arising primarily from the meta substitution of the phenyl rings. At the level of the crystal structure, the flexibility may be associated with slight changes in molecular conformation, torsional angles etc. The curves in figure $6 c$ suggest that major part of these changes which are structurally permitted, occur in the early stages of thermal ageing. Admittedly, the above mentioned correlation between $\varepsilon$ and molecular characteristics is only predictive in nature and has to be confirmed from structural information on heat treated fibres.

Based on the data presented in figure 6 , the time $t_{100}$ and $t_{30}$ needed for 100 and $30 \%$ reductions, respectively in modulus and strength have been calculated and table 1 lists the values. It is noticed that as the temperature decreases, the time needed for deterioration increases quite sharply, indicating the asymptotic nature of the $t_{100}$ vs $T$ curve (not presented). It must be emphasized that the data in table 1 and figure 6 can be utilized to predict the thermal behaviour of Nomex fibres at $T$ 's less than and also intermediate between any of the temperatures chosen in the present study. The results which have emerged thus indicate that when used at elevated temperatures, whether as structural composites or as fibres, deterioration in the initial characteristics occur. It is essential to take into account their influence on the performance of the fibre.

\section{Conclusions}

It has been established that thermal exposures cause deterioration in the initial characteristics of Nomex fibres.
Reductions in X-ray crystallinity, weight, tensile modulus and strength at break are observed. Surface damages in the form of groove like openings, minute holes and material deposits are also introduced. Durations of thermal exposures needed for reaching states of zero tensile strength and modulus have been estimated. All the thermally induced effects are controlled by two parameters, viz. the temperature, $T$ and the duration of the cumulative exposure, $t_{\text {cum }}(T)$.

\section{Acknowledgements}

The authors wish to thank Dr N Balasubramanian and $\mathrm{Mr}$ Basavaraj, Eternit Everest, Bangalore, for carrying out the tensile tests. They also acknowledge Dr T A Bhaskaran's help in recording the micrographs. The authors are indeed grateful to Dr M A Subramanian for providing the Nomex sample.

\section{References}

Carlson D J, Gan L H, Parnell R D and Wiles D M 1973 Polym. Lett. Ed. 11683

DuPont Technical Information Bulletin 1981 NX-16

Hindeleh A M and Abdo Sh M 1989 Polymer 30218

Iyer R V 1999 X-ray and related studies on polymeric materials, Ph.D. Thesis, Bangalore University, Bangalore

Iyer R V and Vijayan K 1994 Polymer science: recent advances (ed.) I S Bhardwaj (New Delhi: Allied Publishers Ltd.) Vol. I, p. 362

Iyer R V and Vijayan K 1998a Macromolecules: New frontiers (ed.) K S V Srinivasan (New Delhi: Allied Publishers Ltd.) Vol. II, p. 847

Iyer R V and Vijayan K 1998b Curr. Sci. 75946

Iyer R V and Vijayan K 1999 Bull. Mater. Sci. 221013

Jain A and Vijayan K 2000 Curr. Sci. 78331

Kakida H, Chatani Y and Tadokoro H 1976 J. Polym. Sci.: Polym. Phys. Ed. 14427

Kasen Geppo 1974 Japan Chemical Fibre Association

Marks N 1995 High performance materials in aerospace (ed.) H M Flower (London: Chapman \& Hall) p. 204

Meredith R 1975 Text. Progr. 7

Parimala H V 1991 Some investigations on the properties and behaviour of Kevlar fibres, M.Phil. Thesis, Mangalore University, Mangalore

Parimala H V and Vijayan K 1993 J. Mater. Sci. Lett. 1299

Shubha M 1989 X-ray investigations on the aramid poly (p-phenylene terephthalamide), M.Phil. Thesis, Mangalore University, Mangalore

Tadokoro H 1979 Structure of crystalline polymers (New York: John Wiley \& Sons) p. 396

Tanner D, Gabarg V and Schaefgen J R 1988 Polymers for advanced technologies, IUPAC international symposium (ed.) M Lewin (New York: VCH Publishers Inc.) p. 408

Tashiro K, Kobayashi M and Tadokoro H 1977 Macromolecules $\mathbf{1 0} 413$

Wakelin J H, Virgin H S and Crystal E 1959 J. Appl. Phys. 30 1654 